\title{
Oral or topical administration of L-arginine changes the expression of TGF and iNOS and results in early wounds healing ${ }^{1}$
}

\author{
Márcio Sousa JerônimoI, Adria do Prado Barros', Vinícius Elord Zen MoritaI III, Erika Oliveira Alves ${ }^{\mathrm{III}}$, Nathalia Lobão Barroso \\ de Souza $^{\text {III }}$, Rosane Mansan de Almeida ${ }^{\mathrm{IV}}$, Yanna Karla Medeiros Nóbrega ${ }^{\mathrm{V}}$, Florêncio Figueiredo Cavalcanti Neto ${ }^{\mathrm{VI}}$, Rivadávio \\ Amorin $^{\mathrm{VII}}$, Maria de Fátima Borin ${ }^{\mathrm{VII}}$, Anamélia Lorenzetti Bocca ${ }^{\mathrm{VII}}$
}

DOI: http://dx.doi.org/10.1590/S0102-865020160090000003

IPhD, Cell Biology Department, Faculty of Medicine, Institute of Biology, Applied Immunology Laboratory, Universidade de Brasília (UnB), Brazil. Design of the study, technical precedures, statistical analysis, manuscript writing.

"Fellow PhD degree, Farmaceutic Science Faculty, UnB, Brasilia-DF, Brazil. Design of the study, technical procedures.

IIIMsC, Farmaceutic Science Faculty, UnB, Brasilia-DF, Brazil. Design of the study, technical procedures.

${ }^{\mathrm{IV}} \mathrm{PhD}$, Associate Professor, Farmaceutic Science Faculty, UnB, Brasilia-DF, Brazil. Design of the study, technical procedures, analysis of data.

${ }^{\vee}$ Full Professor, Pathology Department, Faculty of Medicine, UnB, Brasilia-DF, Brazil. Technical procedures, statistical analysis, analysis of data.

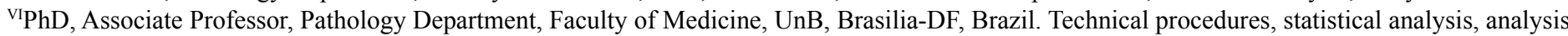
of data.

${ }^{\mathrm{VII}} \mathrm{PhD}$, Associate Professor, Farmaceutic Science Faculty, UnB, Brasilia-DF, Brazil. Design of the study, technical procedures, analysis of data.

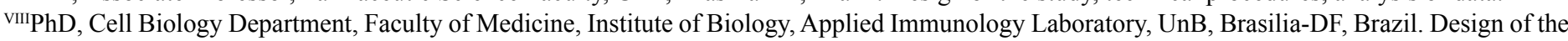
study, statistical analysis, analysis of data, manuscript writing.

\section{ABSTRACT}

PURPOSE: To evaluate the contribution of L-arginine oral or topical rout of administration in the surgical wound healing process.

METHODS: L-arginine was orally or topically administrated to mice after a laparotomy model procedure. The wounds were analyzed to evaluate the granulation tissue by HE analysis, collagen deposition, iNOS and cytokines production by immunochemisyry on wound progress. Mice used in this model were healthy, immunosupressed or diabetic and all of them were treated with different concentration of L-arginine and rout of administration.

RESULTS: Suggested that groups treated with L-arginine orally or topically improved wound repair when compared with non-treatad mice. L- arginine treatment stimulated TGF- $\beta$ and restricted NO production leading to a mild Th1 response and collagen deposition in injured area, when it was orally administrated. Topical administration decreased IL- 8 and CCR 1 expression by wound cells but did not interfere with TNF- $\alpha$ and IL-10 production, ratifying the decrease of inflammatory response, the oral administration however, presented a higher iNOS and TGF- $\beta$ expression then. L-arginine treatment also improved the improved the wound healing in immunosupressed or diabetic mice.

CONCLUSION: L-arginine administrated orally or topically can be considered an important factor in the recuperation of tissues. Key words: Arginine. Wound Healing. Transforming Growth Factor beta. Nitric Oxide. Cytokines. Mice. 


\section{Introduction}

Rapid and efficient tissues repair after trauma-induced immunological injury is critical for preventing infections ${ }^{1}$. Wound healing, both after surgery or tissue injury, is mediated by many different cell types and it is dependent on the production of cytokines and growth factors, as well as adequate nutritional support $^{2}$. The healing process, which occurs after the recruitment of innate and adaptive immune cells to the injury site, is composed of four stages of tissue repair: hemostasis, inflammation, cell proliferation and repair, and tissue remodeling ${ }^{3}$.

Inflammation, an important healing step that occurs between 24 and 72 hours after hemostasis, involves the recruitment of inflammatory cells to the injured site, particularly myeloid cells that contribute to several phases of the immune response. Neutrophils and macrophages, the main myeloid cell types involved in inflammation, are regulated by different nutritional and cytokine environments. Depending on the stimulus, these cells can produce a number of cytokines, such as tumor necrosis factor alpha (TNF- $\alpha$ ), interleukin 8 (IL-8), interleukin 1 (IL-1) and transforming growth factor beta (TGF- $\beta$ ), that participate in the activation and chemotaxis of a wide range of cells ${ }^{4}$. The cell activation process can determine the time of inflammation duration and the beginning of repair phase.

L-arginine metabolism has been described in the activation of myeloid cells. This dibasic amino acid is synthesized de novo from proline, glutamine or glutamate 5 . Advances in nutritional therapy have suggested that dietary supplementation with L-arginine strengthens the immune system due to the participation of L-arginine in protein synthesis, signaling and cell proliferation $^{6}$. However, the effect of L-arginine supplementation on the immune system is still unclear, and its therapeutic application has been controverse. L-arginine can be catabolized by nitric oxide synthase (NOS) or arginase (ARG), producing nitric oxide (NO) and L-citrulline or urea and L-ornithine, respectively? In mammals, ARG exists in two different isoforms, type I arginase (ARG1), a cytosolic enzyme, and type II arginase (ARG2), a mitochondrial enzyme. L-arginine metabolism by ARG promotes fibroblast replication and collagen production, which are important in the early phases of wound healing ${ }^{8}$.

Three different NOS isoforms have been described, differing in their cellular location, catalytic properties and inhibitors. NOS1, also known as nNOS, is prevalent in nervous tissue, whereas NOS2 or iNOS, the inducible form, is present in a range of immune cells and NOS3, or eNOS, can be found in endothelia. NOS isoforms are responsible for the synthesis of NO, which is not only a potent microbicidal mediator of the immune system but it is also a regulator of immediate epithelialization, vascular tone, adhesion molecules expression, leukocyte adhesion, platelet aggregation and angiogenesis ${ }^{9,10}$. Previous works, in animal models or humans, have suggested that $\mathrm{NO}$ is an important constituent of the inflammatory phase of the healing process ${ }^{7}$. The balance between ARG and NOS has been correlated with myeloid cell activation status, and differential L-arginine metabolism seems to lead to divergent outcomes. Furthermore, the impact of NO and L-Arg on the injury repair process is highly dependent on their local concentration and the time point of analysis ${ }^{11}$. Recently, has been demonstrated that L-arginine not only stimulates fibroblast proliferation but also inhibit apotosis in these cells, and the authors showed that this proliferation and survival of the fibroblasts occurs through the activiation of ERK1/2-CREB and PI3K/Akt pathway $^{12}$. Considering the literature data, the aim of this work was to evaluate the contribution of L-arginine oral or topical rout of administration in the surgical wound healing process.

\section{Methods}

All procedures performed on animals were in accordance with the Brazilian College of Animal Experimentation regulations and were approved by the Ethical Committee of Animal Care of the University of Brasilia, DF, Brazil (UnBDOC 62941/2008).

The healthy animals used in these experiments were 6- to 8-week old Swiss male mice, weighing between 20 and 25 $\mathrm{g}$, obtained from the vivarium of the Faculty of Medicine, UnB Brasilia. Diabetics and immunosuppressed mice were obtained by experimental induction of the pathologic conditions on the healthy animals. The animals were kept in individual cages, with food and water access ad libitum, at $22^{\circ} \mathrm{C} \pm 1{ }^{\circ} \mathrm{C}$ and were exposed to cycles of 12 hours light/darkness. Each group had five animals that were randomly distributed. At specific days describe in legends, the animals were euthanized with carbon dioxide $\left(\mathrm{CO}_{2}\right)$ chamber. Blood and wound tissue were obtained by caudal puncture.

\section{Induction of experimental diabetes}

Experimental diabetes was induced by streptozotocin (STZ) (Sigma-Aldrich ${ }^{\circledR}$ ) intraperitoneal administration, with a single dose of $60 \mathrm{mg} / \mathrm{kg}$ body weight, after mice were fasted overnight $^{13}$. Briefly, STZ was dissolved in freshly prepared 0.025 $\mathrm{M}$ citrate buffer $\mathrm{pH}$ 4.5. Animals presenting glycemic plasmatic levels over $200 \mathrm{mg} / \mathrm{dL}, 7$ days after STZ administration were considered diabetics. 


\section{Induction of immunosuppression}

Experimental immunosuppression in mice was induced by intraperitoneal administration of hydrocortisone (União Química Nacional ${ }^{\circledR}$ ) by two consecutive days, with a dose of $25 \mathrm{mg} / \mathrm{kg}$ body weight ${ }^{22}$. Immunosuppression induction was evaluated by leucocytes count in mice blood one day after the last administration of hydrocortisone in comparison with the counting acquired one day before de experimental induction.

\section{Experimental design of Laparotomy}

Anesthesia was performed by intramuscular injection with xylazine $\left(90 \mathrm{mg} / \mathrm{kg}\right.$ body weight) $\left(\mathrm{Ceva}{ }^{\circledR}\right)$ and ketamine (100 mg/kg body weight) (Ceva ${ }^{\circledR}$ ) Brielfy, for laparotomy, the abdomen was shaved, and the skin was disinfected with a $70 \%$ ethanol and $10 \%$ povidone-iodine solution. Surgical procedures were performed under aseptic conditions. A midline 3-cm long laparotomy was carried out and immediately sutured using 5-0 nylon and cylinder needles. After 5 or 10 days after the laparotomy (DAL) treatment, mice were randomly selected for euthanasia.

\section{L-arginine treatment}

\section{Oral administration}

Animals were separated into two groups for these experiments: group 1 (GO1): control animals treated orally with saline solution 7 days before and 7 DAL; and group 2 (GO2): animals treated orally with L-arginine 7 days before and 7 DAL. The L-arginine solution $\left(\operatorname{Vetec}^{\circledR}\right), 2 \mathrm{~g} / \mathrm{kg}$ body weight by day, was administered by gavage. The wounds were daily analyzed during 10 days after the laparotomy.

\section{Topical administration}

Healthy animals were separated into five groups for these experiments and treated in the abdominal region with either glycerol only (GT1, $\mathrm{n}=5$ ) or a dispersion of L-arginine in glycerol at concentrations of 5\% (GT2, n = 5), 10\% (GT3, $n=$ 5), $15 \%(G T 4, n=5)$ and 40\% (GT5, $n=5)$. Diabetic mice were separated in three groups and the treated glycerol only (GD1, $\mathrm{n}=5)$ or with L-arginine at $10 \%(\mathrm{GD} 2, \mathrm{n}=5)$ or $15 \%(\mathrm{GD} 3, \mathrm{n}=5)$. Immunosuppressed animals were also separated in three groups and treated as described above with glycerol only (GI1, n=5) or L-arginine at $10 \%(\mathrm{GI} 2, \mathrm{n}=5)$ or $15 \%(\mathrm{GI} 3, \mathrm{n}=5)$. Each animal received $0.5 \mathrm{~g}$ of glycerol or L-arginine dispersion topically every day from 7 days before to $5 \mathrm{DAL}$. After this period, mice were randomly selected for euthanasia and wounds were analyzed.

\section{Biochemical parameters}

Levels of blood urea nitrogen (BUN), creatinine, alkaline phosphatase, pyruvic acid and oxaloacetic glutamic transaminases were determined from blood samples of animals from groups 1 and 2, collected under anesthesia. Samples were analyzed by spectrometry assay using the Cobas ${ }^{\circledR}$ analyzer (Roche/Hitachi).

\section{Wound analysis}

\section{Tissue preparation}

Fragments $(3 \times 3 \mathrm{~cm})$ of the abdominal tissue containing the scar or normal tissue were removed and fixed in neutral buffered formalin for 6 hours, embedded by routine techniques in paraffin wax and sectioned to $5-\mu \mathrm{m}$ thickness. Sections were subjected to hematoxylin and eosin (HE) or immunohistochemical staining.

\section{Immunohistochemical staining}

Tissue sections of $5-\mu \mathrm{m}$ thickness were collected on gelatin-coated glass slides. The samples were immersed in 3 $\mathrm{mM}$ citrate buffer ( $\mathrm{pH} \mathrm{6.0)}$ ) for 10 minutes at $120^{\circ} \mathrm{C}$ for antigen retrieval, incubated in 3\% bovine serum albumin (BSA) and then incubated with antibodies directed against one of the following marker: TNF- $\alpha$ (1:75 dilution), iNOS, TGF- $\beta$, CCR-1, IL-8, and IL-10 (1:100 dilution). All antibodies were from Santa Cruz Biotechnology, Inc. The sections were incubated with secondary antibodies and streptavidin-biotin complex (DAKO, A/S, Glostrup, Denmark) for 20 minutes. Diaminobenzidine chromogen solution was added to the reactions, and a counter-stain was performed with Mayer's hematoxylin. As a negative control, 1\% BSA was used in place of the primary antibody. Positive controls were also prepared according to the manufacturer's instructions.

\section{Cell counting}

The number of positively-stained cells was determined for each antibody using an integration graticule (Carl Zeiss4740680000000-Netzmikrometer 12.5x). All cells per ten consecutive microscopic high power fields of the operatory wound fragments were counted (x100). At this magnification, each field (integration graticule) has an area equal to $0.015625 \mathrm{~mm}^{2}$. Results were expressed as the mean of positive cells \pm standard deviation (SD) of $\mathrm{n}$ observations per $\mathrm{mm}^{2}$ according to the cell counting method described in previous studies ${ }^{15}$. 


\section{Statistical analysis}

Data were analyzed using the one-way analysis of variance (ANOVA) test followed by Bonferroni or Dunnett's multiple comparison tests. All statistical tests were performed using the software SPSS 10.0.

\section{Results}

\section{Effects of dietary supplementation with L-arginine on wound healing.}

L-arginine supplementation was well-tolerated, as demonstrated by similar serum levels of urea, creatinine, aspartate aminotransferase (AST), alanine aminotransferase (ALT) and alkaline phosphatase in both groups of animals, GO1 (control) and $\mathrm{GO} 2$ (animals orally treated for 10 days with L-arginine at a dosis of $2 \mathrm{~g} / \mathrm{kg}$ body weight/day), as shown in Table 1 . These results indicate that L-arginine supplementation did not affect renal or hepatic activities at the concentration used in the experiments.

TABLE 1 - Biochemical parameters of GO1 and GO2 animals's serum.

\begin{tabular}{ccc}
\hline & GO1 & GO2 \\
\hline Urea $(\mathrm{mg} / \mathrm{dL})$ & $59.00( \pm 8.56)$ & $66.00( \pm 5.95)$ \\
Creatinine $(\mathrm{mg} / \mathrm{dL})$ & $0.40( \pm 0.04)$ & $0.31( \pm 0.03)$ \\
ALT $(\mathrm{U} / \mathrm{L})$ & $191.11( \pm 74.93)$ & $233.8( \pm 91.43)$ \\
AST $(\mathrm{U} / \mathrm{L})$ & $20.22( \pm 1.39)$ & $21.60( \pm 6.63)$ \\
Alkaline phosphatase & $264.22( \pm 152.07)$ & $503.77( \pm 55.97)$ \\
$(\mathrm{U} / \mathrm{L})$ &
\end{tabular}

Control animals (GO1), orally treated with saline solution only 7 days before and 7 days after the laparotomy; GO2- Animals orally treated with L-Arginine $(2 \mathrm{~g} /$ $\mathrm{kg}$ body weight by day) 7 days before and 7 days after the laparotomy; AST- aspartate aminotransferase; ALT- alanine aminotransferase. Statistical analyses were performed by Dunnett's test $(\mathrm{p}>0.05)$.

Histopathological analysis of surgical wounds in group 1 mice presented an intense inflammatory process, without fibrosis appearance, and with migration of polymorphonuclear cells mainly on fifth day after the laparotomy (Figure 1A). On the tenth day after the laparotomy, it was observed a smaller infiltration of polymorphonuclear cells, although the healing process was incomplete (Figure 1C). Similar results were observed for animals supplemented with L-arginine in the pre-operatory phase only (data not shown). Animals in GO2, which received L-arginine supplementation in both pre- and post-operatory phases, exhibited an inflammatory process and polymorphonuclear cell infiltration into a smaller extent; the wound areas exhibited features of a moderate and diffuse inflammatory process without fibrosis and an increase in new vein formation on the fifth day postoperation (Figure 1B). On the tenth day, the wound was almost completely healed (Figure 1D). In addition, collagen fibers were more organized and mature in the wounds of animals from group 2 (Figure 1E), indicating that L-arginine has a positive effect on collagen production. Taken together, these data suggest that oral arginine treatment accelerates and enhances the healing process.
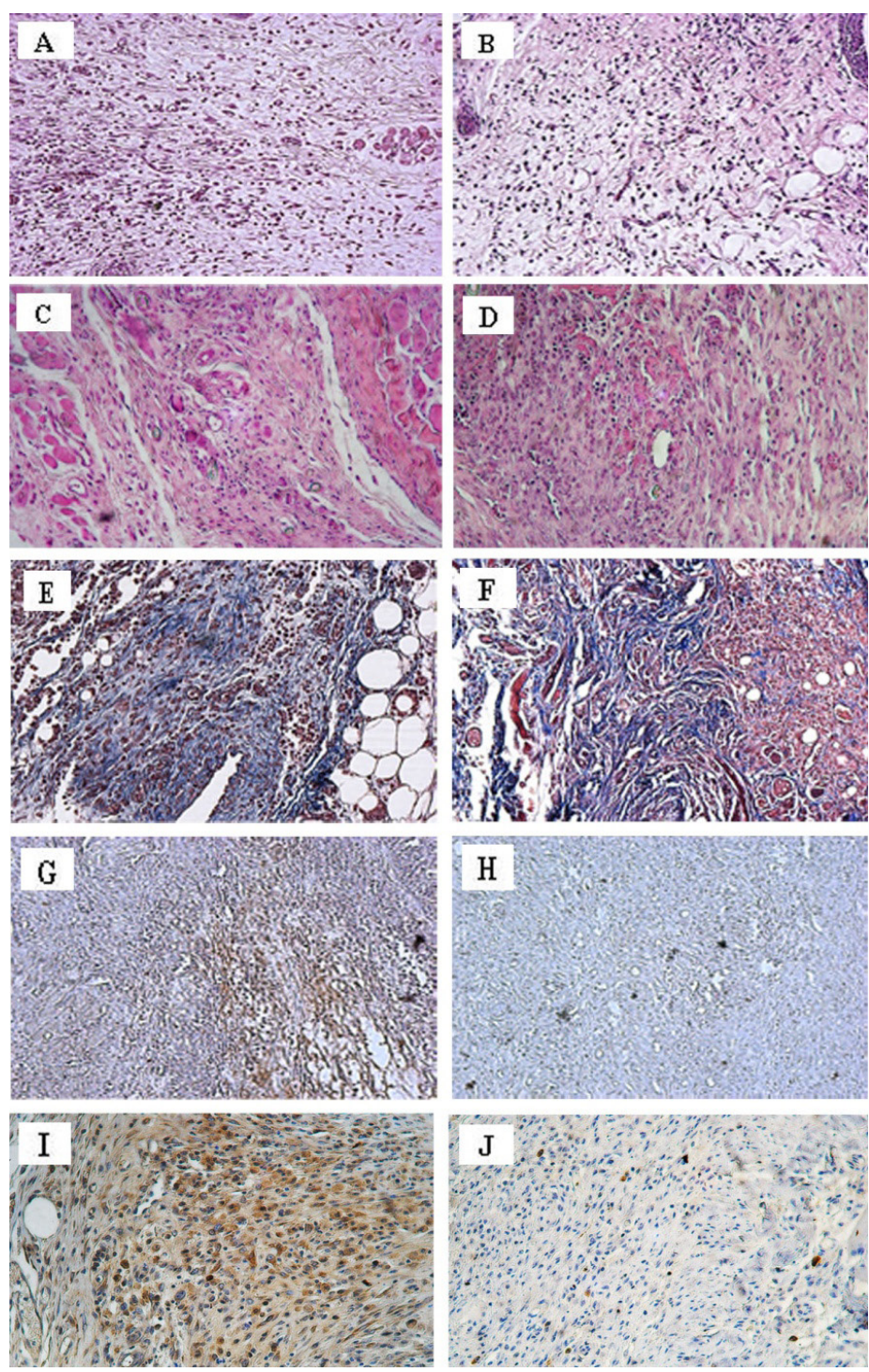

FIGURE 1 - Photomicrography (x200) of HE-stained wound sections from animals in GO1 (A and $\mathbf{C}$ ) and GO2 (B and D). A and B represent 5 DAL; C and D represent 10 DAL. Tissues of animals from GO1 (E) and GO2 (F) were stained with Masson's Trichrome (specific for collagen) 5 DAL and visualized under the microscope (x200). Immunoreactivity of iNOS (x200) in lesion areas of tissues from GO1 animals 5 DAL $(\mathbf{G})$ or 10 DAL $(\mathbf{H})$. Immunoreactivity of TGF- $\beta$ (x200) in lesion areas of tissues from GO2 animals 5 DAL (I) or 10 DAL (J). In GO1, control animals were treated orally with saline solution 7 days before and 7 days after the laparoscopy; and in GO2, animals were treated orally with L-arginine 7 days before and 7 days after the laparoscopy. 
The expression of iNOS and TGF- $\beta$, inflammatory mediators important for the tissue repair process, were also examined. Animals in GO1 exhibited high expression of iNOS on the fifth day after laparotomy compared to expression on the $10^{\text {th }}$ day or in animals not subjected to laparotomy, as depicted in Figures $1 \mathrm{H}$ and 2. For animals in $\mathrm{GO}$, we observed similar levels of iNOS expression on the $5^{\text {th }}$ and $10^{\text {th }}$ DAL (Figure 2); these iNOS levels were comparable to those in control mice 10 days after laparotomy and in normal tissue (iNOS in normal tissue - not subjected to laparotomy $=175.4 \pm 19.5 \mathrm{cell} / \mathrm{mm}^{2} ;$ iNOS in group 1 mice on the $5^{\text {th }} \mathrm{DAL}=441.6 \pm 113.5 \mathrm{cell} / \mathrm{mm}^{2} ;$ iNOS in group 1 mice on the $10^{\text {th }} \mathrm{DAL}=217.5 \pm 76.1 \mathrm{cell} / \mathrm{mm}^{2} ;$ iNOS in GO2 mice $5 \mathrm{DAL}=233.6 \pm 59.7 \mathrm{cell} / \mathrm{mm}^{2}$; iNOS in GO2 mice $10 \mathrm{DAL}$ $=201.6 \pm 56.0 \mathrm{cel} 1 / \mathrm{mm}^{2}$ ). The expression of TGF- $\beta$ in GO1 was significantly different among animals analyzed on the $5^{\text {th }}$ and $10^{\text {th }}$ DAL; animals analyzed on the $10^{\text {th }}$ DAL showed an increase in TGF- $\beta$ production compared to animals that had not undergone the laparotomy, as shown in Figure 2 (TGF- $\beta$ in normal tissue not subjected to laparotomy $=149.6 \pm 9.3 \mathrm{cell} / \mathrm{mm}^{2} ;$ TGF $-\beta$ in group 1 mice on the $5^{\text {th }} \mathrm{DAL}=242.9 \pm 64.1 \mathrm{cell} / \mathrm{mm}^{2}$; TGF- $\beta$ in group 1 mice $\left.10 \mathrm{DAL}=294.4 \pm 70.1 \mathrm{cell} / \mathrm{mm}^{2}\right)$. In GO2 mice, the expression of the cytokine TGF- $\beta$ was higher on the $5^{\text {th }}$ DAL and then decreased on the $10^{\text {th }}$ DAL (TGF- $\beta$ in GO2 mice 5 DAL $=422.4 \pm 78.8 \mathrm{cell} / \mathrm{mm}^{2}$; TGF- $\beta$ inGO2 mice $10 \mathrm{DAL}=188.8$ $\pm 48.6 \mathrm{cell} / \mathrm{mm}^{2}$ ) to levels similar to those observed in normal animals (Figures 1J and 2). Therefore, oral supplementation with L-arginine increased the expression of TGF- $\beta$ and decreased the expression of iNOS in the surgical wounds of $\mathrm{GO} 2$ animals on the $5^{\text {th }}$ day after laparotomy.

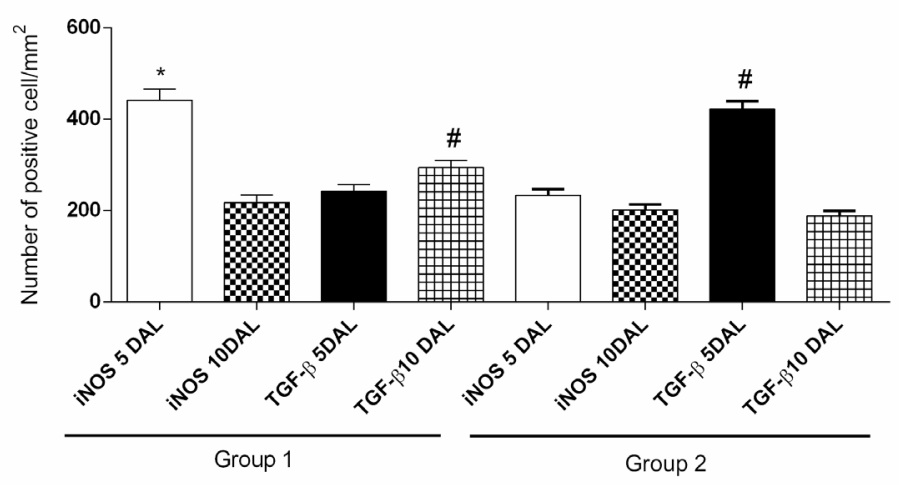

FIGURE 2 - Expression of iNOS and TGF- $\beta$ in wound areas 5 DAL or 10 DAL.. The results represent the means \pm SEM of the number of positive cells per $\mathrm{mm}^{2}$ counted in ten different fields. Immunostaining for iNOS and TGF- $\beta$ in wound areas are shown. * indicates the difference $(\mathrm{p}<0.05)$ relative to normal skin sections stained with antibodies specific for iNOS. \# indicates difference $(\mathrm{p}<0.05)$ relative to normal skin stained with antibodies specific for TGF- $\beta$. Results are representative of two independent experiments $(n=5)$. Statistical analyses were performed by one-way ANOVA followed by Bonferroni's multiple comparison test.

\section{Effect of topical administration of arginine on the wound healing process}

To evaluate whether the topical administration of L-arginine could also enhance the wound healing process, healthy animals were treated with glycerol only (GT1) or with L-arginine at concentrations of 5\% ( GT2), 10\% (GT3), 15\% (GT4) or 40\% (GT5). The results are shown in Figure 3. Animals topically treated with L-arginine showed significantly enhanced healing on the fifth day after the laparotomy. The best results were obtained when L-arginine was used at concentrations of $10 \%$ (Figure 3B and F) and 15\% (Figure 3C and G). In animals of the groupsGT3 and GT4, there was a decrease in polymorphonuclear cell infiltration, a markable neovascularization, inflammation, and a more intense disorganized and diffuse deposition of collagen fibers, especially in animals in GT3 (Figure 3B and F). In animals from the group treated with arginine at $40 \%$ concentration it was observed an intense inflammation process with predominance of polymorphonuclear cells and increased collagen deposition.
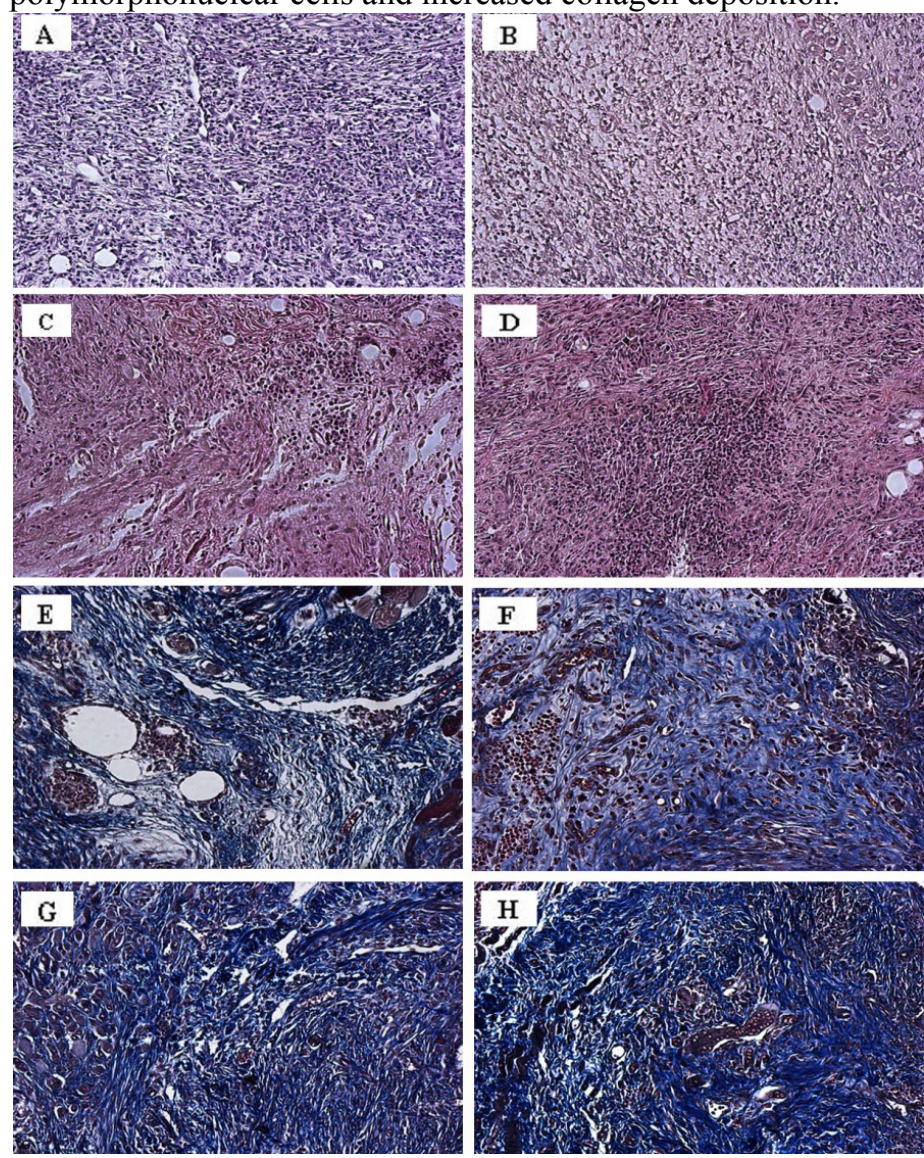

FIGURE 3 - Photomicrography (x200) of wound sections from animals treated topically with different concentrations of L-arginine. Sections were obtained fromGT1 (A and E), GT3 (B and F), GT4 (C and G) and GT5 (D and H) 5 DAL and stained with HE (A-D) or Masson's Trichrome (E-H). In GT1, control animals were treated topically with glycerol; in GT3, animals were treated with 10\% L-arginine; in GT4, animals were treated with $15 \%$ L-arginine; and in GT5, animals were treated with $40 \%$ L-arginine. All animals, except for those in GT1, were treated topically with L-arginine 7 days before and 5 days after the laparotomy. 
The expression of iNOS and TGF- $\beta$ was measured in tissues from animals topically treated with L-arginine (Figures 4 and 5). The expression of iNOS in wound tissue from GT2 and GT3 animals was similar to that observed in GT5 animals (Figures $4 \mathrm{~A}$ and $5 \mathrm{~A}$ ), and the expression of iNOS in the wound tissue of animals in GT4 and GT5 was higher than the control group (Figures 4C and 5A). All groups of animals, except GT1 (control), showed increased expression of TGF- $\beta$ (Figures $4 \mathrm{D}-\mathrm{F}$ and $5 \mathrm{~B}$ ), and animals treated with L-arginine at $10 \%$ exhibited the most marked up-regulation in TGF- $\beta$ expression (Figures 4D and 5B).
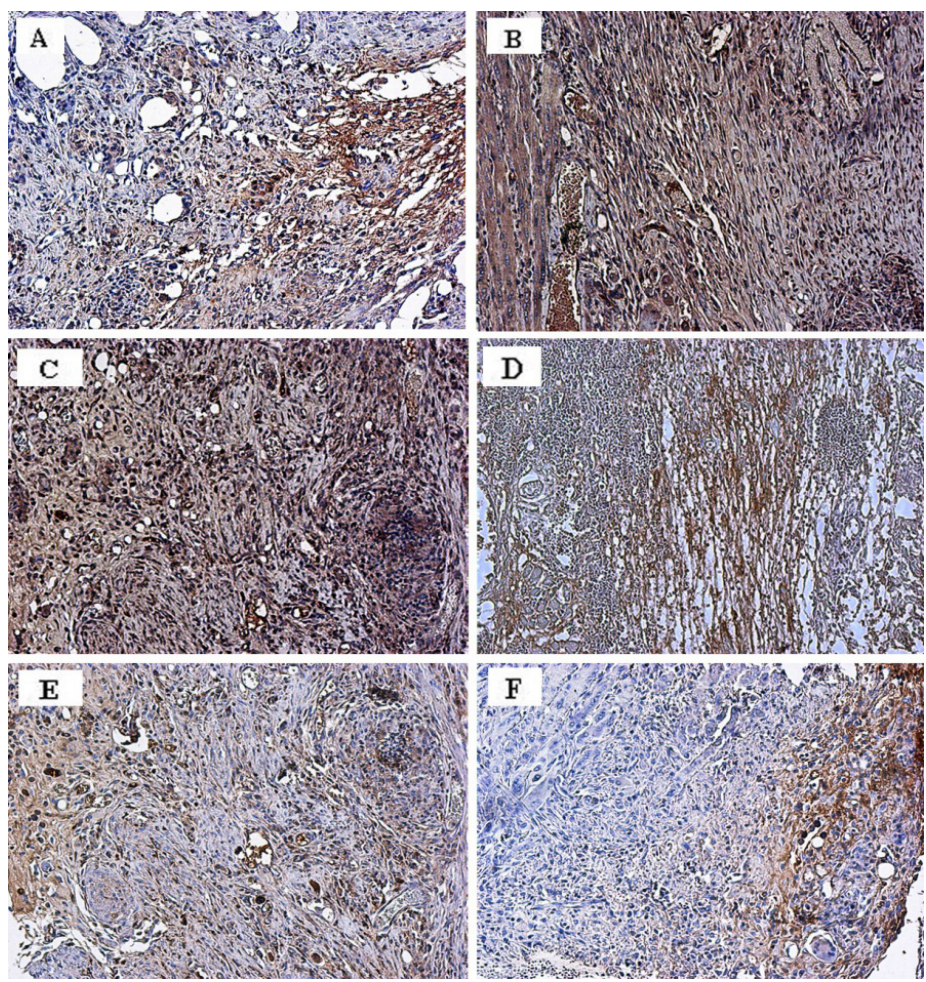

FIGURE 4 - Immunoreactivity of iNOS or TGF- $\beta$ in lesion areas of animals treated topically with different concentrations of L-arginine. Immunohistochemical analysis (x200) are shown for GT3 (A and D), GT4 (B and E) and GT5 (C and F). Sections were incubated with antibodies against iNOS (A-C) or TGF- $\beta$ (D-F) and stained with an avidin-biotin complex. In GT3, animals were treated with $10 \%$ L-arginine; in GT4, animals were treated with $15 \%$ L-arginine; and in GT5, animals were treated with $40 \%$ L-arginine. All animals were treated topically with L-arginine 7 days before and 5 days after the laparotomy.
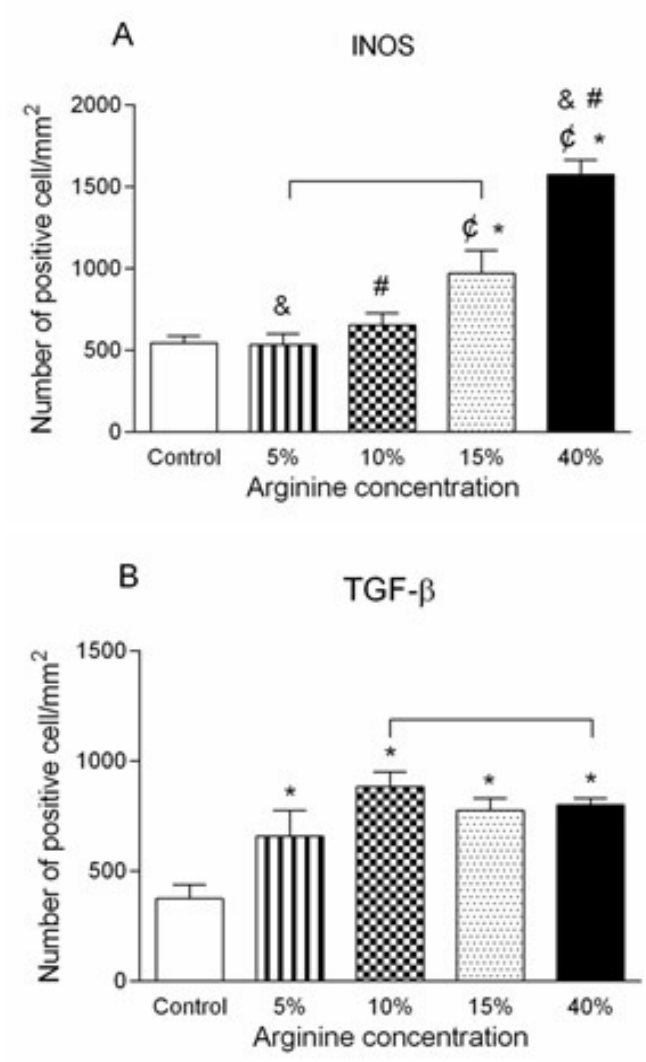

FIGURE 5 - Expression of iNOS and TGF- $\beta$ in wound areas. The results represent the means \pm SEM of the number of positive cells per $\mathrm{mm}^{2}$ counted in ten different fields. Immunostaining for iNOS (A) and TGF- $\beta(\mathbf{B})$ in wound areas are shown. *indicates the difference $(\mathrm{p}<0.05)$ relative between control group and animal treated whit L-Arginine at $5 \%, 10 \%, 15 \%$ and $40 \%$. \& indicates the diference $(\mathrm{p}<0.05)$ relative between animals treated with $5 \%$ or $40 \%$ of L-Arginine. \# indicates the diference $(\mathrm{p}<0.05)$ relative between animals treated with $10 \%$ or $40 \%$ of L-Arginine. $\phi$ indicates diference $(p<0.05)$ relative between animals $15 \%$ or $40 \%$ of L-Arginine. All animals $(\mathrm{n}=5)$ were treated topically with L-arginine or vehicle (glycerol) alone 7 days before and 5 days after the laparotomy. The results are representative of two independent experiments. Statistical analysis were performed using one-way ANOVA test followed by Bonferroni's multiple comparison test.

Other important proteins in the maintenance the of inflammatory process had their expression evaluated in animals from GT1, GT3 and GT5, including TNF- $\alpha$, IL-8, IL-10 and CCR-1 (Figure 6). TNF- $\alpha$ expression was higher in wounds tissues of animals in GT5, whereas TNF- $\alpha$ expression was similar in the wounds tissues of animals in GT1 and GT3 (Figure 6A). IL-8 expression was lower in the wounds areas in animals from GT3 and it was higher in the wounds areas in animals from GT5 when compared to control group (Figure 6B). IL-10 expression in the wounds tissues of animals in group 7 was significantly 
higher than in the wounds tissues of animals in GT1 (Figure 6C). CCR-1 expression was also down-regulated in the wounds areas of animals in GT3 and up-regulated in animals from GT5 when compared to control (Figure 6D).
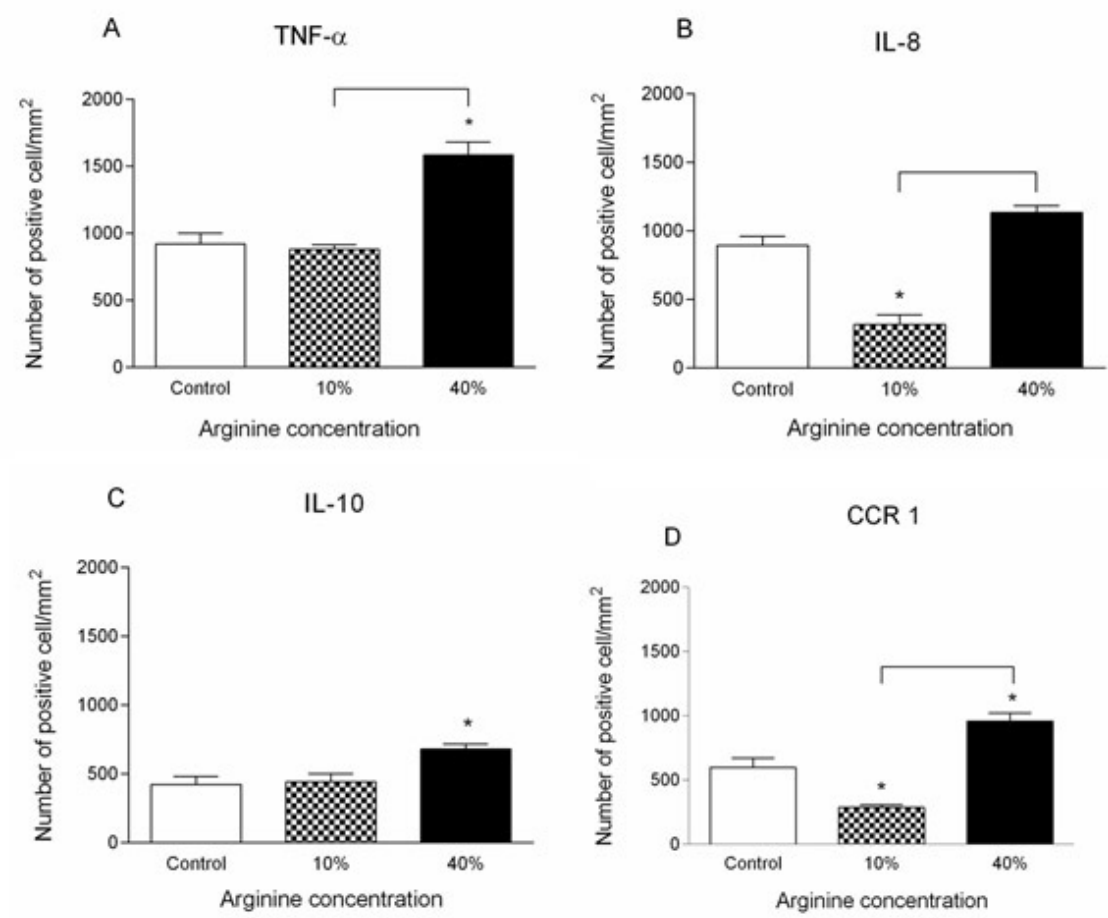

FIGURE 6 - Expression of TNF- $\alpha$, IL-8, IL-10 and CCR1 in wound areas. The results represent the means \pm SEM of the number of positive cells per $\mathrm{mm}^{2}$, counted in ten different fields. Immunostaining for TNF- $\alpha(\mathbf{A})$, IL-8 (B), IL-10 (C) and CCR1 (D) in wound areas are shown. * indicates the difference $(p<0.05)$ relative to control. The animals were treated with glycerol only; $10 \%$ L-arginine; or with $40 \% \mathrm{~L}$-arginine. All animals $(\mathrm{n}=5)$ were treated topically with L-arginine or vehicle (glycerol) 7 days before and 5 days after the laparotomy. Results are representative of two independent experiments. Statistical analysis were performed using one-way ANOVA followed by Bonferroni's multiple comparison test.

\section{Effect of topical administration of L-arginine on the wound healing of immunosuppressed or diabetic mice}

Pathologic conditions, as diabetes and immunosuppression, were induced in mice and they were submitted to same experimental design described before in order to evaluate the influence of L-arginine in wound healing processes. Diabetic and immunosuppressed mice were topically treated with glycerol only (GD1, diabetic; GI1, immunosuppressed), or with L-arginine at concentrations of $10 \%$ (GD2, diabetic; GI1, immunosuppressed) or 15\% (GD3, diabetic; GI3, immunosuppressed).

Diabetic animals topically treated with $10 \%$ or $15 \%$ of L-arginine, respectivelyGD2 and GD3, showed significant enhanced healing on the $5^{\text {th }}$ day after the laparotomy, when compared with control, GD1 (Figure 7D, E and F) that showed polymorphonuclear cells infiltration, loose connective tissue and discreet neovascularization. On the other hand, in the groups treated with 10 or $15 \%$ of L-arginine, there were observed a small amount of mononuclear cells, well-structured conjunctive tissue, newly formed vessels and glands. Experimental immunosuppression induced on animals was confirmed by the decreasement in their leucocytes counting, which was significatively different after hydrocortisone administration (data not showed). Just like as healthy and diabetic animals, the immunosuppressed mice topically treated with L-arginine showed a different hystological pattern of wound process when compared with control group (Figure 7 D-F). L-arginine topical administration promoted changes in tissue morphology, like as the presence of granulation tissue and on collagen deposition aspects. It was possible to observe a more heterogeneous morphologic pattern, with a remarkable inflammatory process in groups of animals treated with $10 \%$ of L-arginine (Figure 7E). Groups treated with $15 \%$ of L-arginine showed a homogeneous morphologic pattern, with a 
mild inflammatory process showing isolated polymorphonuclear cells (Figure 7F). Tissues obtained from groups of diabetic and immunosuppressed animals treated with $10 \%$ or $15 \%$ of L-arginine, when stained with Masson trichrome method, showed a relative increase of collagen deposition (data not shown).
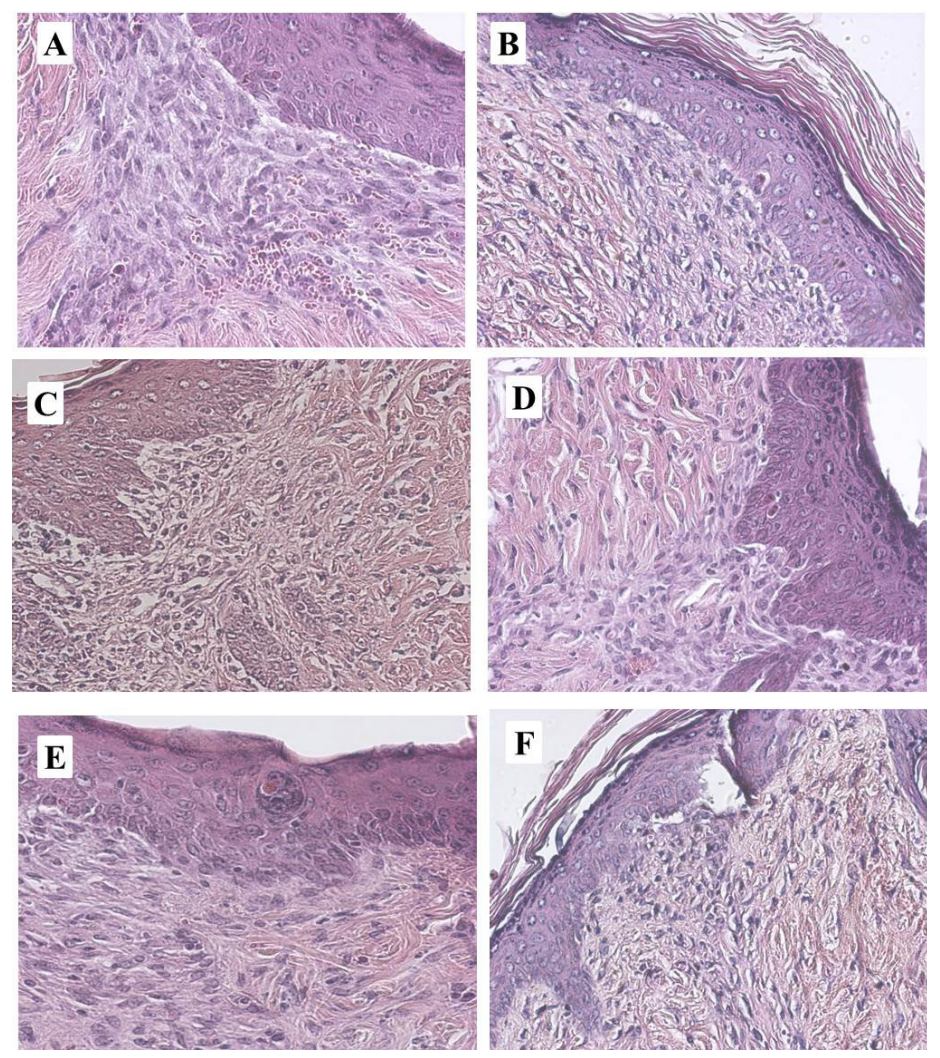

FIGURE 7 - Photomicrography (x200) of HE-stained wound sections from immunosuppressed (A-C-E) and diabetic (B-D-F) animals treated topically with different concentrations of L-arginine 7 days before and 5 days after the laparotomy. All groups are analyzed in 5 DAL and the animals were treated topically with vehicle (glycerol) (A-B); $10 \%$ L-arginine(C-D) or with $15 \%$ L-arginine.

\section{Comparison between topical and oral administra- tion of L-arginine on the wound healing}

Comparing both administration route, oral (GO2 euthanized 5 days after laparotomy) and topical (GT3) corresponding to same dosis administration and observation conditions in health mice submitted to laparotomy, the results show that there were no significative difference in expression of iNOS or TGF- $\beta$ between control groups, GT1 or GO1 (5 DAL).

When groups treated with $50 \mathrm{mg}$ of L-arginine by day varying only the administration route, topical (GT3) or oral (GO2) 5DAL, were compared, the expression of iNOS was higher in animals topically treated, and there was an extremely significative $(p<0.0001)$ difference between the groups caused by the administration route. The same significative difference $(p<0.0001)$ was observed when the expression of TGF- $\beta$ was analyzed comparing animals treated orally or topically with the same L-arginine dosis.

\section{Discussion}

Wound healing is a multi-step process that involves the coordinate action of matrix components, cytokines and growth factors ${ }^{16}$. Enzymes involved in L-arginine metabolism, including ARG and iNOS, are widely distributed in many different tissues.

The present study demonstrates the beneficial effects of L-arginine on healing processes when orally or topically administered, either in healthy, immunosuppressed or diabetic mice. Arginine influenced expression of cytokines and growth factors involved in the healing process. The exact mechanism underlying the wound healing effect of arginine remain unclear ${ }^{12}$, but previous animal studies have suggested that arginine metabolites are envolved in the wound healing process ${ }^{12}$. Lately, Hol et al. ${ }^{11}$ demonstrated that major surgeries has a higher decreasement on plasma levels of ornithine and NO than that observed in minor surgeries.

Other previous work has established the importance of L-arginine in successful wound healing ${ }^{17}$, demonstrating that the impaired NO synthesis in the diabetic wound environment can be reversed, at least partially, by arginine supplementation. Their results suggested that L-arginine supplementation restores decreased healing in the acute wound model by normalizing the NO pathway without affecting arginase activity. Other experimental data suggested that the different arginine metabolic pathways are sequentially activated, and NO and ornithine levels are specifically elevated in wound fluids when compared to plasma $^{18}$, and that different arginine metabolites could influence the early phases of healing induced by NO application ${ }^{19}$. Fujiwara et al. ${ }^{12}$, demonstrated that L-arginine supplementation stimulates fibroblast proliferation and also promote an anti-apoptotic effect in these cells, and the efects occur through activation of GPRC6A along with the activation of ERK1/2-CREB and PI3K/Akt pathway.

NO is a reactive nitrogen oxide specie that has been intensively studied for decades. NO also participates in inflammation by interfering with the activation of macrophages and T cells. iNOS expression and NO production are associated with Th1 immune responses, but overexpression of $\mathrm{NO}$ is associated with immunosuppression ${ }^{20}$. 
In the present work, oral or topical administration of L-arginine were evaluated in post surgical wound healing process. The results showed a decrease in the expression of iNOS in animals in which L-arginine was orally administered in comparision to the control animals. In parallel with histopathological analysis, the results suggested that the inflammatory process was attenuated five days after laparotomy, when tissues showed a decreased NO production, and it could had decreased the immunosuppressive mecanisms associated with high NO levels. However, as the tissues were first analysed on the fifth day after laparotomy, iNOS expression could have been high in the early stages of healing, since inflammation and tissue repair start quickly following lesion manifestation. It would be in accordance with the study realized by Finnen et al. ${ }^{19}$ that showed early healing after NO application.

By the other hand, topical administration of L-arginine at $40 \%$ was detrimental to tissue repair, as suggested by high levels of iNOS expression in tissues and histopathological analysis that indicated an acute inflammatory process. The intensity of the inflammatory process and cytokines envolved will determine if NO participates as a microbicidal or immunosuppressive agent ${ }^{21}$. Filipin et $a l .{ }^{22}$ showed, in an experimental model of crush injury, that damage occurred with an intensive inflammatory reaction accompanied by increased oxidative damage, increased cytokine mRNA transcription and TGF- $\beta$ growth factor expression in the gastrocnemius muscle. The treatment with a NO synthase inhibitor markedly decreased the histological and molecular damages and increased collagen formation. These data corroborate with results found in the present work.

In this study, animals topically treated with L-arginine at $40 \%$ showed increased expression of IL-8 in the fifth day after laparotomy, probably due to the high intensity of inflammation process stablished, as well as the increased number of polymorphonuclear cells and NO production at the site of injury. In contrast, animals topically treated with L-arginine at $10 \%$ expressed significantly lower levels of IL-8 when compared with control animals, possibly as a result of their accelerated wound healing. IL-8 expression could have been higher at earlier stages of tissue repair, such as during the inflammatory phase, and could have enhanced angiogenesis (23), which would have contributed to faster healing. However, the time point chosen for tissue evaluation did not allowed the verification of this hypothesis.

Another important cytokine to the wound healing process is TGF- $\beta$, which activates genes associated with type I collagen production $^{24}$ and promotes collagen production by fibroblasts ${ }^{25}$. TGF- $\beta$ can promote collagen production by stimulating the arginase pathway as well as it is able to inhibit the iNOS pathway and result in an increase ornithine production by increasing the availability of arginine for arginase ${ }^{26}$. It was observed a significant increase in TGF- $\beta$ levels in tissues of animals treated with L-arginine, either orally or topically, compared to those of control animals, and it was also observed that in topical treatment there was a higher expression of TGF- $\beta$ than in the tissues of animals orally treated. It is tempting to speculate that the stimulation of macrophages with L-arginine leads to the production of TGF- $\beta$, which enhances collagen deposition by fibroblasts. L-arginine could also act indirectly by suppressing Th1 immune responses through the inhibition of Th1 cytokines, as indicated by the lower expression of iNOS in oral treatment ${ }^{6}$.

The expression of IL-10 in the tissue of animals treated with L-arginine at $10 \%$ were similar to that found in the animals treated with glycerol only suggesting that, in this case, L-arginine did not affect the expression of IL-10. However, when animlas were topically treated with L-arginine dispersion at $40 \%$ of concentration, a significative change was observed, with a higher production of IL-10 in the tissue. Eming et al. ${ }^{27}$ demonstrated that mice deficient for the anti-inflammatory cytokine interleukin 10 (IL-10 $0^{-/}$) showed a accelerated wound healing, with a closed excisional wounds significantly earlier compared with IL-10competent control littermates. The authors discussed that this effect was attributable to a combination of accelerated epithelialization as well as increased wound contraction in the mutant animals. IL$10^{-/}$wound tissue contained more macrophages than wounds from control mice and formed a highly cellular granulation tissue ${ }^{27}$. Peranteau et al. ${ }^{28}$ investigated if IL-10 overexpression could decrease inflammation and create an environment conducive to scarless wound healing in adults. The authors concluded that this was an approach to be taken with caution, since wound healing process is composed by a serie of tightly regulated events whose attempt manipulation may result in unintended consequences. The results presented by the authors suggested that the IL-10 overexpression acts providing an environment supportive of a regenerative healing process that is characteristic of scarless wound healing ${ }^{28}$. However, despite the accelerated wound closure showed by Eming et al. ${ }^{29}$ in IL-10 deficient mice, the mechanical strength of wounds in IL-10-deficient mice is reduced, indicating that IL-10 affects the quality of the repaired tissue ${ }^{27,28}$. In Peranteau et al. ${ }^{28}$ study, overexpression of IL-10 resulted in a decreased inflammatory infiltrate and a more organized collagen deposition. It is interesting to notice that when mice were topically treated with dispersion of L-arginine at $40 \%$, there was an increase in the IL-10 expression and in this same group of animals it was observed an increased collagen deposition. Since 
the administration of $40 \%$ L-arginine improved the expression of iNOS, the increased expression of IL-10 could be a compensation mechanism to control the inflammatory process, but it also could has acted as a mechanism to acquire a more organized collagen deposition, as occurred in the Peranteau et al. ${ }^{28}$ work. This, IL10 expression control it is another rote to be investigated in the relation of L-arginine administration and collagen deposition.

CCR1 gene encodes a member of the beta chemokine receptor family, which belongs to a family of $\mathrm{G}$ protein-coupled receptors. Among the ligands of this receptor are macrophage inflammatory protein 1 alpha, monocyte chemoattractant protein 3 , and myeloid progenitor inhibitory factor-1. Chemokines are critical for the recruitment of effector immune cells to the site of inflammation ${ }^{30}$. The levels of CCR1, which is expressed in lymphocytes, monocytes and eosinophils, decreased in animals topically treated with $10 \%$ L-arginine. This suggests an adicional evidence of the enhanced healing in the injured tissue. Histopathological analysis demonstrated a milder inflammatory process, suggesting that a higher expression of CCR 1 could have occurred in an early phase of tissue repair, which is more dependent on lymphocytes, monocytes and eosinophils. Likewise occurred in the case of the IL-10 analysis, animals treated with L-arginine at $40 \%$ showed an increasement in the CCR1 expression, what can be occurring to compensate the more intense inflammation installed in the tissue.

\section{Conclusions}

Either topical or oral administration of L-arginine improves the wound healing process. For oral treatments, on fifth day after laparotomy, with daily L-arginine administration, TGF- $\beta$ production was stimulated and NO levels were lower, leading to a reduced Th1 response and increased collagen deposition in the injured area. For topical treatments, the results showed a higher level of iNOS and TGF- $\beta$ on the wound environment, suggesting an accelerated healing process. Overall, these results suggest that L-arginine, either oral or topically applied, may be an important factor in the recuperation of tissues following injury, and topically applied could be even more effective in accelerate the wound healing process.

\section{References}

1. Stahel PF, Smith WR, Moore EE. Role of biological modifiers regulating the immune response after trauma. Injury. 2007;38:140922. PMID: 18048034

2. Park J, Barbul A. Understanding the role of immune regulation in wound healing. Am J Surg. 2004;187:11S-6. PMID: 15147986.
3. Gurtner GC, Werner S, Barrondon Y, Longaker M. Wound repair and regeneration. Nature 2008;453:314-21. PMID: 18480812.

4. Kisseleva T, Brenner D. Mechanisms of fibrogenesis. Exp Biol Med. 2008;233:109-22. PMID: 18222966.

5. Wu G, Bazer FW, Davis TA, Kim SW, Li P, Rhoads JM, Satterfield MC, Smith SB, Spencer TE, Yin Y, Arginine metabolism and nutrition in growth, health and disease. Amino Acids. 2009;37:15368. PMID: 19030957.

6. Popovic PJ, Zeh H, Ochoa J. Arginine e immunity. J Nutr. 2007;137:1681S-6. PMID: 17513447.

7. Hol JW, Van Lier F, Valk M, Klimek M, Stolker RJ, Fekkes D. Effect of major and minor surgery on plasma levels of arginine, citrulline, nitric oxide metabolites, and ornithine in humans. Ann Surg. 2013;258(6):1072-8. doi: 10.1097/SLA.0b013e3182856ade.

8. Schreml S, Szeimies RM, Prantl L, Landthaler M, Babilas P. Wound healing in the 21st century. J Am Acad Dermatol. 2010;63(5):86681. doi: 10.1016/j.jaad.2009.10.048.

9. Bronte $\mathrm{V}$, Zanovello P. Regulation of immune responses by L-arginine metabolism. Nat Rev Immunol. 2005;5:641-54. PMID: 16056256.

10. Tong BC, Barbul A. Cellular and physiological effects of arginine. Mini Rev Med Chem. 2004;4:823-32. PMID: 15544543.

11. Ochoa JB, Bernard AC, Mistry SK, Morris SM, Figert PL, Maley ME, Tsuei BJ, Boulanger BR, Kearney PA. Trauma increases extrahepatic arginase activity. Surgery. 2000;127(4):419-26. PMID: 10776433.

12. Fujiwara $\mathrm{T}$, Kanazawa $\mathrm{S}$, Ichibori $\mathrm{R}$, Tanigawa $\mathrm{T}$, Magome $\mathrm{T}$, Shingaki K, Miyata S, Tohyama M, Hosokawa K. L-arginine stimulates fibroblast proliferation through the GPRC6A-ERK1/2 and PI3K/Akt pathway. Plos One. 2014;9(3):e92168. PMID: 24651445.

13. Joussen AM, Doehmen S, Le ML, Koizumi, K Radetzky, S Krohne, TU Poulaki, V Semkova, I Kociok. TNF-alpha mediated apoptosis plays an important role in the development of early diabetic retinopathy and long-term histopathological alterations. Mol Vis. 2009;15:1418-28. PMID: 19641635.

14. Bodinet C, Lindequist U, Teushchen E, Freudenstein J. Effect of orally applied herbal immunomodulator on cytokine induction an antibody response in normal and immunossupressed mice. Phytomedicine. 2002;9:606-13. PMID: 12487324.

15. Sá VZ, Silva TA, Reis CMS, Cunha FQ, Figueiredo F, Bocca AL. The pattern of immune cell infiltration in chromoblastomycosis: involvement of macrophage inflammatory protein-1 alpha/CCL3 and fungi persistence. Rev Inst Med Trop São Paulo. 2007;49(1):4953. PMID: 17384820.

16. Guo S, DiPietro LA. Factors affecting wound healing. J Dent Res. 2010;89(3):219-29. doi: 10.1177/0022034509359125.

17. Witte MB, Thornton FJ, Tantry U, Barbul A. L-arginine supplementation enhances diabetic wound healing: Involvement of the nitric syntase and arginase pathways. Metab Clin Exp. 2002;51(10):1269-73. PMID: 12370845.

18. Zunić G, Supić G, Magić Z, Drasković B, Vasiljevska M. Increased nitric oxide formation followed by increased arginase activity induces relative lack of arginine at the wound site and alters whole nutritional status in rats almost within the early healing period. Nitric Oxide. 2009;20(4):253-8. doi: 10.1016/j.niox.2009.01.005.

19. Weller R, Finnen MJ. The effects of topical treatment with acidified nitrite on wound healing in normal and diabetic mice. Nitric Oxide. 2006;15(4):395-9. PMID: 16731016.

20. Schleifer KW, Mansfield JM. Suppressor macrophages in African trypanosomiasis inhibit $\mathrm{T}$ cell proliferative responses by nitric oxide and prostaglandins. J Immunol. 1993;151(10):5492-5503. PMID: 8228241. 
21. Gutierrez FRS, Mineo TWP, Pavanelli WR, Guedes PMM, Silva JS. The effects of nitric oxide on the immune system during Trypanosoma cruzi infection. Mem Inst Oswaldo Cruz. 2009;104(1):236-45. PMID: 19753479.

22. Filippin LI, Cuevas MJ, Lima H, Marroni NP, Gallego JG, Xavier RM. The role of nitric oxide during healing of trauma to the skeletal muscle. Inflamm Res. 2011;60:347-56. doi: 10.1007/s00011-0100277-2.

23. Petreaca ML, Yao M, Liu Y, DeFea K, Martins-Green M. Transactivation of vascular endothelial growth factor receptor-2 by interleukin-8 (IL-8/CXCL-8) is required for IL-8/CXCL-8 induced endothelial permeability. Mol Biol Cell. 2007;18:5014-23. PMID: 17928406.

24. Hsu Y, Hsiao M, Chien YW, Lee WR. Exogenous nitric oxide stimulated collagen type I expression and TGF- $\beta 1$ production in keloid fibroblasts by a cGMP-dependent manner. Nitric Oxide. 2007 16, 258-65. PMID: 17052928.

25. Werner S, Grose R. Regulation of wound healing by growth factor and cytokynes. Physiol Rev. 2003;83:835-70. PMID: 12843410.

26. Stechmiller JK, Childress B, Cowan L. Arginine supplementation and wound healing. Nutr Clin Pract. 2005;20:52-61. PMID: 16207646.

27. Eming SA, Werner S, Bugnon P, Wickenhauser C, Siewe L, Utermp hlen O, Davidson JM, Krieg T, Roer A. Accelerated wound closure in mice deficient for interleukin-10. Am J Pathol. 2007;170(1):188202. PMID: 17200193

28. Peranteau WH, Zhang L, Muvarak N, Badillo AT, Radu A, Zoltick PW, Liechty KW. IL-10 Overexpression decreases inflammatory mediators and promotes regenerative healing in an adult model of scar formation. J Invest Dermatol. 2008;128(7):1852-60. PMID: 18200061.

29. Eming SA, Werner S, Bugnon P, Wickenhauser C, Siewe L, Utermöhlen O, Davidson JM, Krieg T, Roers A Accelerated wound closure in mice deficient for interleukin-10. Am J Pathol. 2007;170(1):188-202. PMID: 17200193.
30. Luster A, Alon R, von Adrian UH. Immune cell migration in inflammation: present and future therapeutic targets. Nat Immunol. 2005;6:1182-90. PMID: 16369557.

\section{Acknowledgement}

To Viviane Monteiro Leal for immunohistochemical staining technical support.

\section{Correspondence:}

Anamélia Lorenzetti Bocca

Laboratório de Imunologia Aplicada, Departamento de Biologia Celular Instituto de Biologia - UnB

Bloco J, sala J1 28/8 - Campus Darcy Ribeiro - Asa Norte

70910-900 Brasília - DF Brasil

Tel.: (55 61)3107-3056

albocca@unb.br

Received: May 21, 2016

Review: July 19, 2016

Accepted: Aug 18, 2016

Conflict of interest: none:

Financial sources: CAPES, CNPq, FINATEC, DPP/UnB, and FAPDF (process number 2009/00334-0)

${ }^{1}$ Research performed at Applied Immunology Laboratory, Biology Institute, Universidade de Brasília (UnB), Brazil. 